\title{
Role of beta-stabilizing elements on the microstructure and mechanical properties evolution of modified PM Ti surfaces designed for biomedical applications
}

\author{
J. Ureña ${ }^{a}$, E. Tejado ${ }^{b}$, PY. Pastor ${ }^{b}$, F. Velasco ${ }^{a, c}$, S. Tsipas, A. Jiménez-Morales ${ }^{a, c}$ and E. Gordo \\ ${ }^{a}$ University Carlos III of Madrid, Leganés, Spain; ${ }^{b}$ Departamento de Ciencia de Materiales-CIME, Universidad Politécnica De Madrid, Madrid, \\ Spain; 'Alvaro Alonso Barba Technological Institute of Chemistry and Materials, IAAB, University Carlos III of Madrid, Leganés, Spain
}

\begin{abstract}
This work focuses on the evaluation of modified surfaces on Ti produced by powder metallurgy. These newly designed surface modifications are achieved by deposition and diffusion of a stable aqueous suspension prepared in one case from micro-sized $\mathrm{Nb}$ powder (Ti $\beta$-stabilizer element) and in another case from $\mathrm{Nb}$ plus the addition of ammonium chloride, $\mathrm{NH}_{4} \mathrm{Cl}$, (thermo-reactive diffusion process). Different design parameters such as diffusion element ( $\mathrm{Nb}$ or $\mathrm{Mo}$ ), state of the Ti substrate (green or sintered) and the treatment process (diffusion or thermo-reactive diffusion) lead to all the surface-modified materials, GreenTi-Nb, SintTi$\mathrm{Nb}$ and $\mathrm{Ti}-\mathrm{Nb}_{\mathrm{NH} 4 \mathrm{Cl}}$, GreenTi-Mo, SintTi-Mo and Ti-Mo $\mathrm{NH}_{4 \mathrm{Cl}}$. The modified Ti surfaces present a gradient in composition and microstructure $(\beta / \alpha+\beta / \alpha$ phases) resulting in an improvement in some of their mechanical properties: (1) higher micro-hardness in all the modified materials and (2) lower elastic modulus (more similar to that of the human bone) in those without $\mathrm{NH}_{4} \mathrm{Cl}$.
\end{abstract}

ARTICLE HISTORY

Received 23 October 2017

Accepted 23 December 2017

KEYWORDS

Titanium; surface-

modification; powder

technology; microstructuralgradient; elastic modulus; hardness

\section{Introduction}

The great interest of titanium alloys in the biomedical sector is well known due to their suitable characteristics for biomaterials compared to other metallic materials. However, there are still some concerns regarding titanium alloys such as the high Young's modulus which is superior to that of human bone, the low wear resistance and the toxic effect of $\mathrm{Al}$ and $\mathrm{V}$ of some alloys on the long term $[1,2]$. Among the desired properties of biomaterials, the mechanical ones are considered of high importance since an improvement in hardness together with a decrease in modulus of elasticity would enhance the service life period of implants [2, 3]. A large variety of properties can be achieved with titanium due to two main characteristics: (1) crystalline structure (hcp or bcc) with $\alpha, \alpha+\beta$ or $\beta$ phase according to the $\beta$-transus temperature $[4,5]$; and (2) high susceptibility of being modified through surface modification treatments.

High specific strength is one of the main requirements for implants, and titanium has the most suitable value among the metallic biomaterials in this aspect [6]. However, the design of $\beta-\mathrm{Ti}$ alloys emerges as a response to the necessity of improving other poorer aspects such as stiffness. $\beta-\mathrm{Ti}$ alloys have low Young's modulus while maintaining or enhancing the material strength by incorporating biocompatible elements such as $\mathrm{Mo}, \mathrm{Nb}, \mathrm{Zr}$ or $\mathrm{Ta}$ which makes them ideal for biomedical applications $[1,4,6]$. Furthermore, Mo and
$\mathrm{Nb}$ exhibit complete solubility in $\mathrm{Ti}$ above $882^{\circ} \mathrm{C}$ which allows a microstructural change and thus, the modification of their properties [4,7]. However, a large amount of these alloying elements is required to maintain stable $\beta$ phase at room temperature which raises the price and density of these alloys [8]. For this reason, the surface modification with $\beta$-stabilising elements is employed as a strategy to improve the surface properties while maintaining the lightness of $\mathrm{Ti}$ in the core.

Regarding surface modification, a wide variety of processes and techniques are employed for the enhancement of mechanical, biological and chemical properties of implants. Depending on the aspect to improve, the most widely used are: (i) For wear resistance, nitriding techniques such as diffusion, ionplasma, laser, high-energy plasma methods for TiN synthesis $[9,10]$ or laser cladding [11]; (ii) for corrosion resistance, physical and chemical vapour deposition [12], chemical/thermal treatment [13], thermal oxidation/spraying, plasma spray, ion implantation, micro-arc oxidation, sandblasting or electrochemical treatments; and iii) for mechanical performance and biocompatibility, developing $\beta$ alloys by introduction of $\mathrm{Nb}, \mathrm{Zr}, \mathrm{Mo}, \mathrm{Ta}$ or $\mathrm{Sn}$ [8], or physical or chemical treatments such as wet etching, anodisation or laser/plasma exposition [14,15]. A summary of these surface modifications has been reported in Refs. [16,17]. 
In this work, the diffusion of two different $\beta$-stabiliser elements, $\mathrm{Nb}$ or Mo, has been the approach followed toward enhancing the mechanical performance by reducing the modulus of elasticity and improving hardness. This approach modifies the surface properties of $\mathrm{Ti}$, maintaining its lightness in the core. The modified Ti surfaces have been processed in two stages: (i) fabrication of Ti substrates by conventional powder metallurgy route of pressing and sintering, benefiting from the cost-effectiveness of this processes $[18,19]$; and (ii) a heat treatment to promote the diffusion of the deposited elements on the $\mathrm{Ti}$ substrates $[5,8]$. Therefore, the results of this paper are presented and discussed based on the influence of microstructure and chemical composition on the mechanical properties of different surface modifications performed as a function of diffusion element ( $\mathrm{Nb}$ or Mo), state of the Ti substrate (green or sintered) and diffusion process (with or without activating agent).

\section{Experimental procedure}

\subsection{Materials and sample preparation}

The materials processed classified by their design parameters together with the nomenclature used further on are summarised in Table 1.

The surface modification carried out with niobium as diffusion element led to GreenTi-Nb, SintTi-Nb and $\mathrm{Ti}-\mathrm{Nb}_{\mathrm{NH} 4 \mathrm{Cl}}$ materials, whereas the molybdenum diffusion resulted in GreenTi-Mo, SintTi-Mo and $\mathrm{Ti}-\mathrm{Mo}_{\mathrm{NH}} \mathrm{Cl}$ materials. All the six modified surfaces were studied and compared to Ti control as the reference material. First, the fabrication of the Ti substrates was carried out by using hydride-dehydride commercially pure titanium powder (cpTi grade 4) (GfE Metalle und Materialien $\mathrm{GmbH}$, Germany) with a particle size below $75 \mu \mathrm{m}$, and a mean particle size of $45 \mu \mathrm{m}$. The green Ti substrates were produced by uniaxial pressing at $600 \mathrm{MPa}$ using a cylindrical die of $16 \mathrm{~mm}$ in diameter with lubricated walls using zinc stearate. For the sintered $\mathrm{Ti}$ substrates, a sintering cycle in high vacuum $\left(10^{-5}\right.$ mbar $)$ at $1250^{\circ} \mathrm{C}$ for $2 \mathrm{~h}$

Table 1. Surface-modified Ti materials studied with their design parameters.

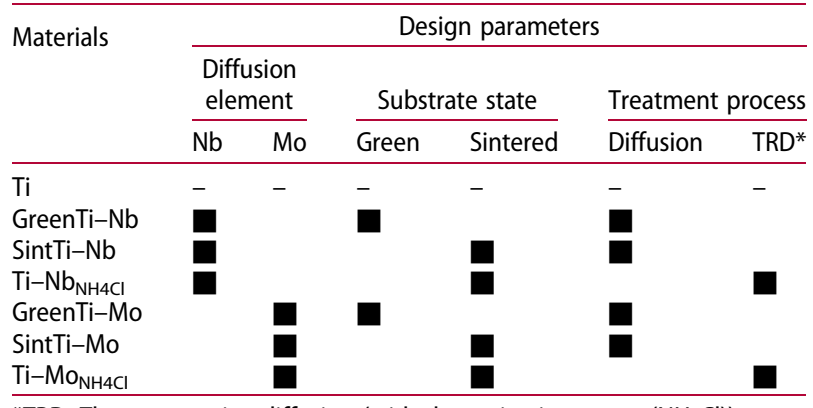

*TRD: Thermo-reactive diffusion (with the activating agent $\left(\mathrm{NH}_{4} \mathrm{Cl}\right)$ ). with a heating and cooling rate of $5^{\circ} \mathrm{C} \min ^{-1}$ was applied after pressing. Then, the surface modification by $\mathrm{Nb}$ was performed depositing an aqueous suspension of niobium powder with a particle size between 1 and $5 \mu \mathrm{m}$ (Alfa Aesar, Germany). A suspension containing $10 \%$ volume $\mathrm{Nb}$ particles was prepared in water and sprayed at room temperature onto the powder metallurgy (PM) Ti substrates in two different states: green $\mathrm{Ti}$ compact (as-pressed) and sintered $\mathrm{Ti}$ in order to obtain two different final materials. Before the niobium deposition, the surfaces of the sintered Ti substrates were prepared through grinding with 180\# SiC paper and cleaning in an ethanol ultrasonic bath in order to remove any possible oxide formed. Then, the suspension was sprayed on green and sintered substrates. The $\mathrm{Nb}$ diffusion treatment was performed through a heat treatment in high vacuum $\left(10^{-5} \mathrm{mbar}\right)$ for $3 \mathrm{~h}$ at $1100^{\circ} \mathrm{C}$ and cooling at $5^{\circ}$ $\mathrm{C} \min ^{-1}$, obtaining the labelled GreenTi-Nb and Sint $\mathrm{Ti}-\mathrm{Nb}$ materials. The same process was carefully followed to prepare the Mo suspension and obtain the GreenTi-Mo and SintTi-Mo materials as reported in a previous work [20]. Alternative to the high vacuum diffusion process, $\mathrm{Ti}-\mathrm{Nb}_{\mathrm{NH} 4 \mathrm{Cl}}$ and $\mathrm{Ti}-\mathrm{Mo}_{\mathrm{NH} 4 \mathrm{Cl}}$ materials were obtained through thermo-reactive diffusion in a controlled Ar atmosphere. An addition of $1.5 \%$ of $\mathrm{NH}_{4} \mathrm{Cl}$ (activating agent) was added to the niobium or molybdenum suspension to obtain the $\mathrm{Ti}-$ $\mathrm{Nb}_{\mathrm{NH} 4 \mathrm{Cl}}$ and $\mathrm{Ti}-\mathrm{Mo}_{\mathrm{NH} 4 \mathrm{Cl}}$, respectively. Both materials were subjected to a thermo-reactive diffusion process in $\mathrm{Ar}$ atmosphere at $1100^{\circ} \mathrm{C}$ with a dwell time of $3 \mathrm{~h}$ and a heating and cooling rate of $5^{\circ} \mathrm{C} \mathrm{min}^{-1}$. Finally, before each test, all the diffusion-treated surfaces were finished by a soft grind with a $1200 \#$ SiC emery paper followed by ultrasonic bath in propanol for 5 $\min$.

\subsection{Microstructural and chemical analysis}

The cross-section of all the materials was examined to analyse microstructure and phase transformation by an FE-SEM (FEI Teneo) equipment. Chemical composition analysis was performed by an EDAX equipment in terms of profile and detailed mapping analysis. For this purpose, the cross-section of the materials was prepared by grinding with $\mathrm{SiC}$ emery paper from 180\# to $1200 \#$ grade and polishing down to $0.3 \mu \mathrm{m}$ alumina suspension.

\subsection{Mechanical testing: surface Vickers micro- hardness, surface macro-indentation and cross- sectional nanoindentation}

Vickers micro-hardness was measured on the surfaces of the materials, applying a load of $100 \mathrm{~g}\left(\mathrm{HV}_{0.1}\right)$ for $10 \mathrm{~s}$ with a diamond tip in a Zwick Roell micro-hardness tester and processed by the ZH $\mu$ HD software. 
Six measurements were performed on each material in order to get a reliable average.

Macroscale surface indentation measurements were performed, and Vickers hardness, elastic modulus and maximum indentation depths were determined applying a load of $5 \mathrm{~N}$ with a speed for load application of $0.5 \mathrm{~mm} \mathrm{~min} \mathrm{~m}^{-1}$ and a speed for load removal of $2 \mathrm{~mm}$ $\min ^{-1}$ in a Zwick Roell Z 2.5 tester. The effect of load was studied applying a bigger load of $15 \mathrm{~N}$. Mean $\mathrm{E}$ and $\mathrm{H}$ values of all the materials were expressed as the average of six different measurements.

Nanoindentation measurements in the cross-section were performed to obtain a more precise response and evaluate the effect of microstructure and chemical composition on hardness and elastic modulus. They were carried out to a depth of $500-750 \mathrm{~nm}$ with $10 \mathrm{mN}$ as maximum load by using a standard Berkovich tip calibrated by fused silica. The measurements were performed in an MTS Nanoindenter equipment in profiles from the outer area to the inner part. The average values were calculated by three measurements at different points of the diffusion layers and substrate areas.

\section{Results and discussion}

\subsection{Microstructure and chemical characterisation}

Figure 1 shows the microstructure of the three modified $\mathrm{Ti}-\mathrm{Nb}$ surfaces. A gradient of microstructure and composition was observed in Figure 1( $a$ and $b$ ) with diffusion areas of $100-120 \mu \mathrm{m}$ depth depending on the initial state of the $\mathrm{Ti}$ substrate. $\mathrm{Nb}$ diffusion changed the microstructure of $\alpha$-single-phase titanium into a gradient of $\beta \rightarrow \alpha+\beta \rightarrow \alpha$ phases moving inward. Moving towards the external surface, the $\alpha+$ $\beta$ lamellae appeared closer together, becoming a single $\beta$ region rich in $\mathrm{Nb}$ (detailed in-view from Figure 1(a)). In the case of the surface modification in green substrate (Green Ti-Nb), the diffusion area of $120 \mu \mathrm{m}$ confirms the successful surface modification in a single step during a co-sintering process. On the other hand, Figure 1(b) shows the surface modification carried out in sintered $\mathrm{Ti}$ substrate (Sint $\mathrm{Ti}-\mathrm{Nb}$ ) which is homogeneous and reaches about $100 \mu \mathrm{m}$ depth. Both micrographs present brighter zones in the upper part corresponding with the rests of non-diffused niobium particles which remain adhered to titanium. An energy dispersive X-ray (EDS) profile was taken from Figure 1 (b) to observe the distribution of the elements along the depth. From this analysis, it can be stated that the first $10 \mu \mathrm{m}$, approximately, correspond to the total diffusion of $\mathrm{Nb}$ in the $\mathrm{Ti}$ matrix due to its high solubility into titanium according to the $\mathrm{Ti}-\mathrm{Nb}$ phase diagram [7]. Moving inwards, the niobium content starts to decrease while the amount of titanium increases, and the $\alpha-\beta$ phase appears in the microstructure. The niobium content in the $\mathrm{Nb}$-rich region was of $90 \%$, decreasing until $50 \%$ at a depth of $10 \mu \mathrm{m}$ and varying between $30 \%$ and $10 \%$ as the beta lamellae become more separated. Similar $\mathrm{Ti}-\mathrm{Nb}$ diffusion profiles simulated at the same temperature as ours have been reported in the recent literature [4]. The peaks observed in the composition profile correspond to the separated $\beta$ lamellae, becoming almost zero at the depth of $100 \mu \mathrm{m}$. However, a different structure was found for the $\mathrm{Ti}-\mathrm{Nb}_{\mathrm{NH} 4 \mathrm{Cl}}$ material (Figure 1(c)) created by a thermo-reactive diffusion process with the addition of an activating agent to stimulate the diffusion phenomena due to the formation of volatile $\mathrm{Nb}$ chlorides. This method has been already used in other investigations with the aim of increasing surface hardness and creating diffusion layers [13,21]. Owing to the addition of the ammonium chloride activator, titanium nitride is created on the surface, leading to a)

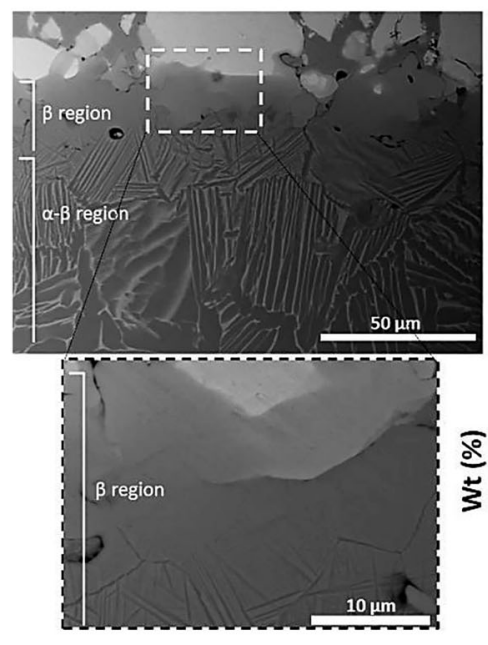

b)
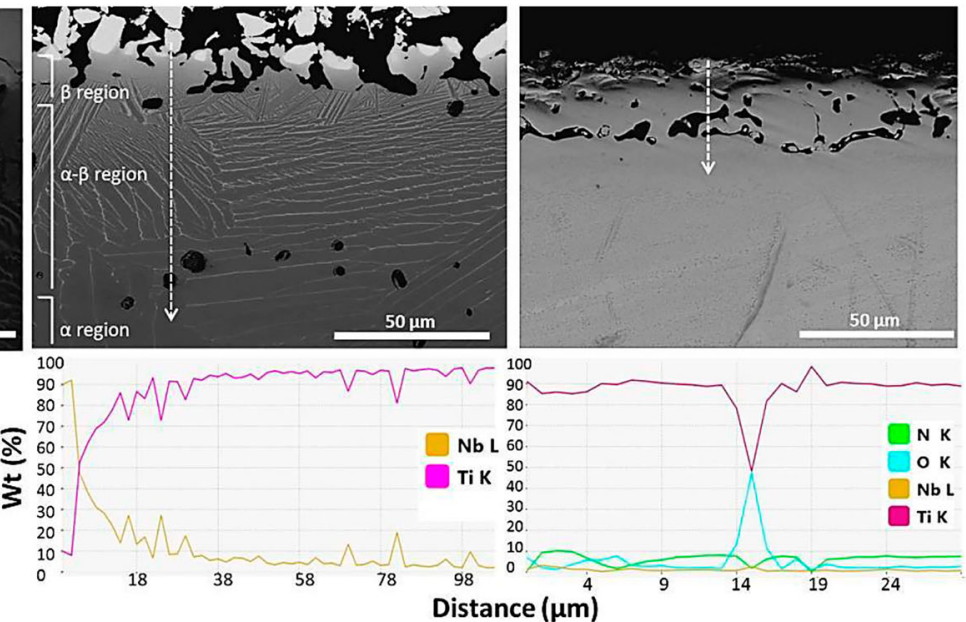

Figure 1. BSE SEM micrographs of the cross-section for the modified PM Ti surfaces with niobium: (a) GreenTi-Nb, (b) SintTi-Nb and (c) $\mathrm{Ti}_{-}-\mathrm{Nb}_{\mathrm{NH} 4 \mathrm{Cl}}$. Diffusion areas and EDS profiles. 
some nitrogen diffusion inwards which can improve the material surface hardness. The $\alpha+\beta$ regions were not identified in that case, and $\mathrm{Nb}$ remained on the surface in very low percentage. Some porosity typical from the thermo-reactive diffusion process appeared in the upper part [21]. As expected, the EDS profile indicated some nitrogen diffusion of almost $10 \%$, constant in the first micrometres. The strong oxygen peak corresponds to a pore since the chemical analysis was performed crossing the porous area. This porosity may be an interesting result from a biomedical point of view to improve cell attachment and proliferation [22].

Besides $\mathrm{Nb}$ diffusion, $\beta$-phase formation from $\alpha$ structure has been achieved by molybdenum diffusion (Figure 2). Molybdenum diffusion seemed to act in the same way as niobium: creating the $\beta \rightarrow \alpha+\beta \rightarrow \alpha$ microstructural gradient together with a Ti-Mo compositional gradient (Figure 2(b)). The surface modification was also performed on green and sintered $\mathrm{Ti}$ substrates (Figure 2( $\mathrm{a}$ and $\mathrm{b})$ ), respectively. A detailed view of the $\beta$-region is shown in Figure 2(a). From the EDS profile analysis (Figure 2(b)), it was possible to observe that the upper part corresponds to a 10$\mu \mathrm{m}$ Mo-rich region of approximately $60 \%$ Mo diffused in and $40 \% \mathrm{Ti}$. The Mo content decreases from surface inwards up to $90 \mu \mathrm{m}$ depth. As a result, a diffusion layer of similar characteristics was obtained for the SintTi-Mo and for the SintTi-Nb materials. Similar results were expected due to the analogous properties for both elements (Mo and $\mathrm{Nb}$ ) and very similar phase diagrams. However, niobium seems to reach a slightly higher diffusion depth than molybdenum as well as an external part richer in niobium (90\%) than in molybdenum (60\%). This can be ascribed to higher diffusion coefficients for $\mathrm{Ti}-\mathrm{Nb}$ systems as stated in Refs. $[4,23]$. On the other hand, the thermo-reactive diffusion process originated the porous $\mathrm{Ti}-\mathrm{Mo}_{\mathrm{NH} 4 \mathrm{Cl}}$ where the EDS graph shows a small diffusion of molybdenum and oxygen in the first micrometres and the nitrogen content remaining almost constant between $5 \%$ and $10 \%$. This TiN surface (Figure 2(c)) can be compared to similar results reported in Ref. [21], showing an agreement between the porosity created by the activator and the absence of beta lamellae due to the nitrogen diffusion.

Figure 3 shows the element distribution (Figure 3 (a)) and a detailed view of the beta lamellae (Figure 3 (b)) formed on Sint Ti-Nb materials. In Figure 3(a), it can be seen how the $\alpha+\beta$ region appears within the first $8-\mu \mathrm{m}$ region due to the fact that the $\beta$-stabiliser content is not enough to retain the $\beta$-phase. Figure 3 (b) presents a detailed micrograph of the $\alpha+\beta$ region together with an EDS mapping. As a result of $\mathrm{Nb}$ diffusion, the $\beta$ lamellae were randomly formed with broader and thinner zones becoming more dispersed in the bottom area due to the decreasing $\mathrm{Nb}$ content. Regarding the phase quantification for a determined area of the $\alpha+\beta$ region, $17 \%$ of $\beta$-phase was found whereas the rest corresponds to the $\alpha$-phase.

\subsection{Mechanical properties:}

\subsubsection{Surface Vickers micro-hardness $\left(H V_{0.1}\right)$}

Surface micro-hardness results on the modified surfaces are shown in Figure 4. Higher values were found with respect to bare $\mathrm{Ti}$ in the range of 2.9-3.1 GPa for the Ti-Nb surfaces and 3.6-4.2 GPa for the Ti-Mo. These values are comparable to those obtained in other related studies with similar Mo [24] or $\mathrm{Nb}$ contents [25], although slightly higher values were reported for $\mathrm{Ti}-\mathrm{Nb}$ compositions with higher sintering temperature [7]. However, when comparing the co-sintered and the diffusion-treated samples, considerably higher differences were observed on the a)
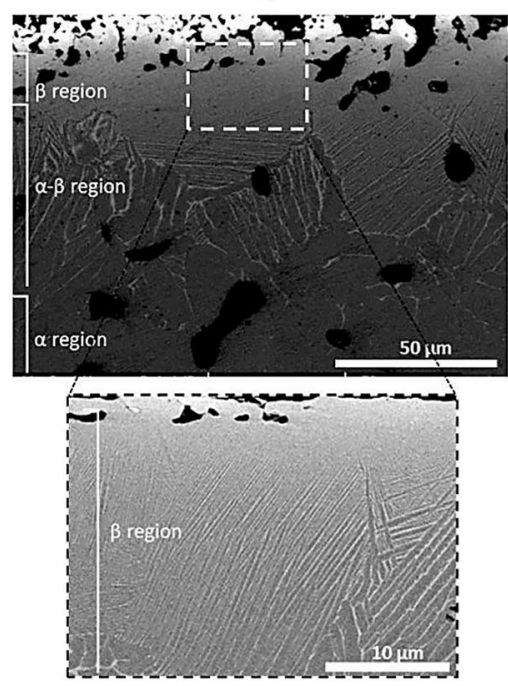

b)
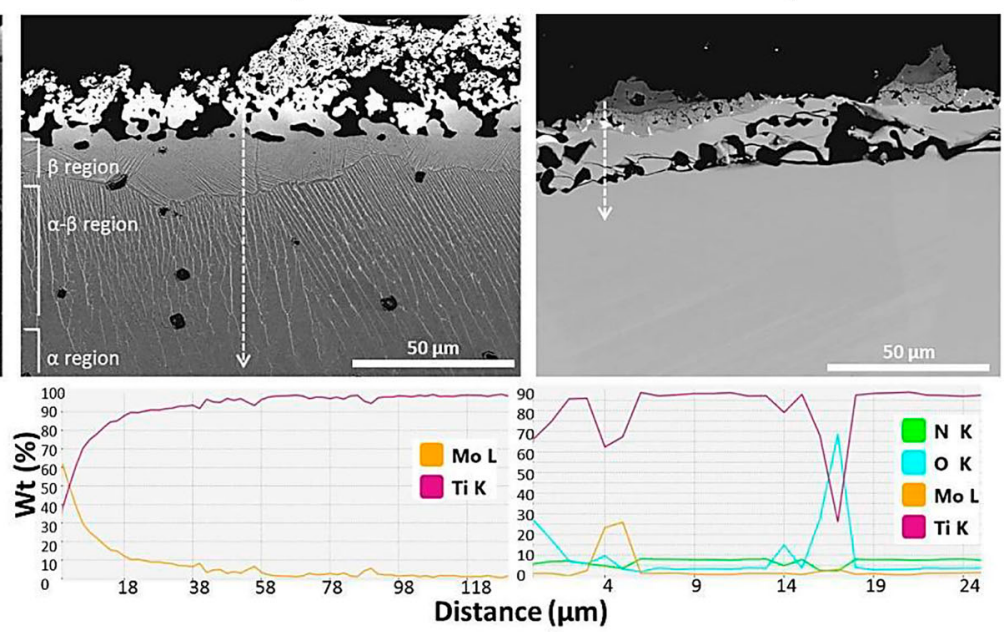

Figure 2. BSE SEM micrographs of the cross-section for the modified PM Ti surfaces with molybdenum: (a) GreenTi-Mo, (b) SintTi$\mathrm{Mo}$ and (c) Ti-Mo $\mathrm{NH}_{4 \mathrm{Cl}}$. Diffusion areas and EDS profiles. 
a)

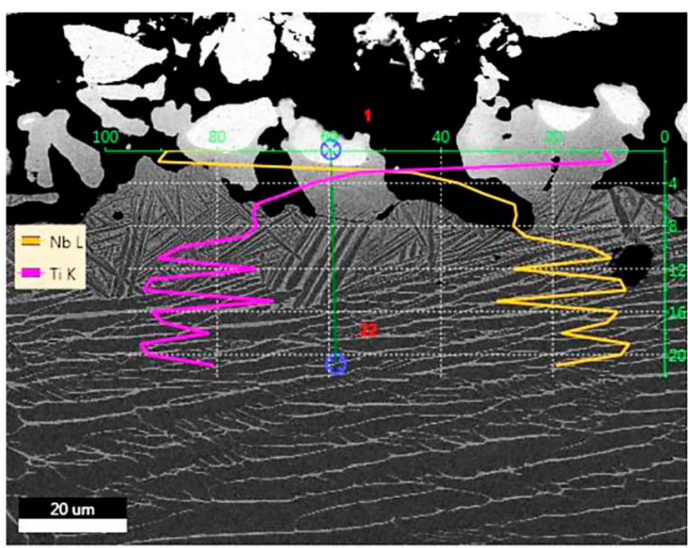

b)

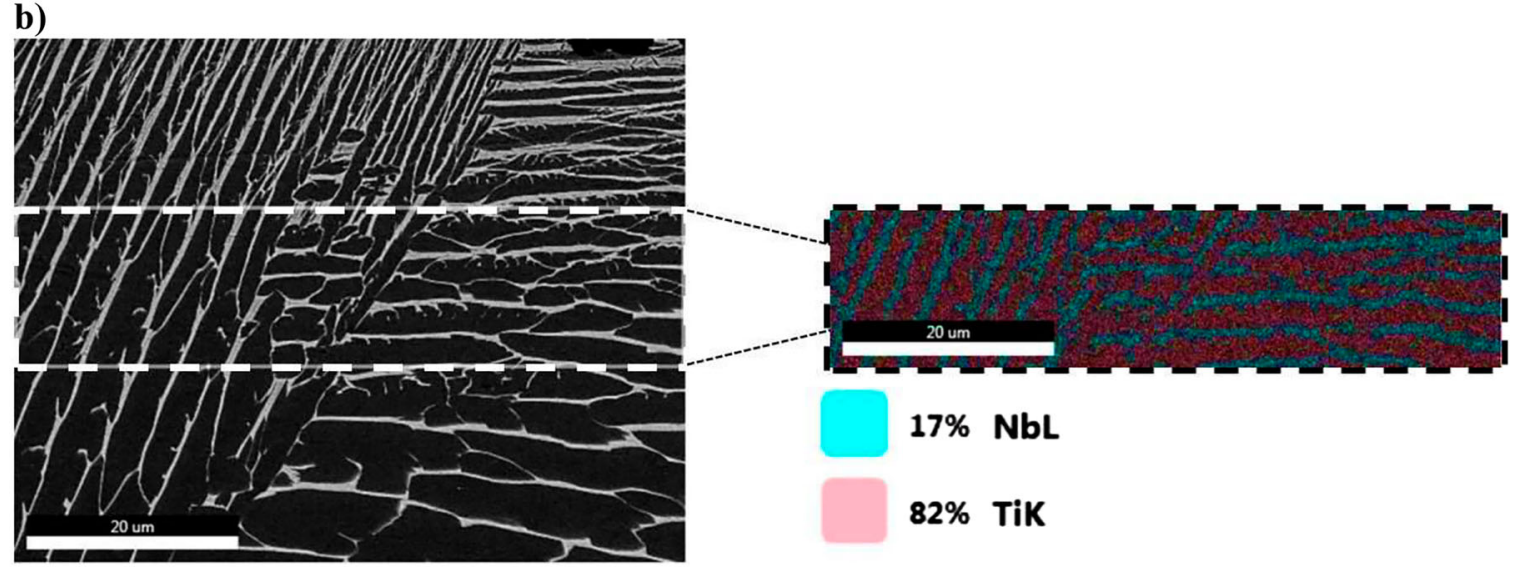

Figure 3. (a) Profile line analysis and (b) phase mapping showing the element distribution and phase transformation for the SintTi$\mathrm{Nb}$ material.

Ti-Mo materials. This can be ascribed to the porosity and homogeneity of microstructures shown in Figures 1 and 2, where both of $\mathrm{Ti}-\mathrm{Nb}$ surfaces exhibit similar diffusion layers, whereas GreenTi-Mo presents higher porosity than SintTi-Mo.

Another interesting issue is the higher average hardness noticed clearly on the modified Ti samples with $\mathrm{Nb} / \mathrm{Mo}$ and the addition of the activator. As expected, the TiN created on these surfaces together with some nitrogen diffusion lead to an increase in hardness near to 8.6 and $10.1 \mathrm{GPa}$, respectively, which means more than three times the hardness of titanium. The difference between $\mathrm{Nb}$ and Mo may be related to the higher hardenability of Mo probably due to a higher solid solution strengthening effect [14]. In this context, it appears that $\mathrm{Nb}$ diffusion is slightly higher than $\mathrm{Mo}$ and thus, the formation of a higher amount of softer $\beta$ phase can be affecting the hardening effect. The increased average surface micro-hardness of the samples agrees with diffusion studies employing this technique to improve wear resistance and oxidation behaviour [26,27].

\subsection{2. $5 \mathrm{~N}$ and $15 \mathrm{~N}$ indentation: surface elastic modulus and macro-hardness}

In order to evaluate the hardness response of these materials at the macroscale, load-unload curves at
$5 \mathrm{~N}$ and $15 \mathrm{~N}$ load were performed. From them, hardness and elastic modulus were obtained and represented in Figure 5. Regarding hardness, similar average values for both loads without significant difference were found. Nevertheless, the hardest surfaces $\left(\mathrm{Ti}-\mathrm{Mo}_{\mathrm{NH} 4 \mathrm{Cl}}\right.$ and $\left.\mathrm{Ti}-\mathrm{Nb}_{\mathrm{NH} 4 \mathrm{Cl}}\right)$ showed higher susceptibility to load since a decrease of around one order of magnitude was observed. This could be ascribed to their diffusion areas (Figures 1(c) and 2(c)) with the high porosity along the first $20-30$ micrometres. Porosity is considered as one of the most relevant aspects that could affect hardness. Therefore, it can be noticed that the halide activator leads to a high increase in hardness as well as a higher susceptibility to load. Comparing micro-hardness $\left(\mathrm{HV}_{0.1}\right)$ and macro-hardness $(15 \mathrm{~N})$ tests, slightly smaller values with bigger load can be observed. This is known as indentation size effect which means higher hardness with low loads [28].

Regarding stiffness, a decrease in elastic modulus is reached on the $\beta$-Ti surfaces as a result of the surface modification by $\beta$-stabilising element diffusion. The elastic modulus values obtained for both $\mathrm{Ti}-\mathrm{Nb}$ and $\mathrm{Ti}-\mathrm{Mo}$ were around $95 \mathrm{GPa}$, reaching a value of $80 \mathrm{GPa}$ in the case of the co-sintered surface as a consequence of higher porosity. Similar values are reported for some metallic biomaterials such as 93,78 and $75 \mathrm{GPa}$ for $\mathrm{Ti}-10 \mathrm{Mo}, \mathrm{Ti}-15 \mathrm{Mo}$ and $\mathrm{Ti}-20 \mathrm{Mo}$, 


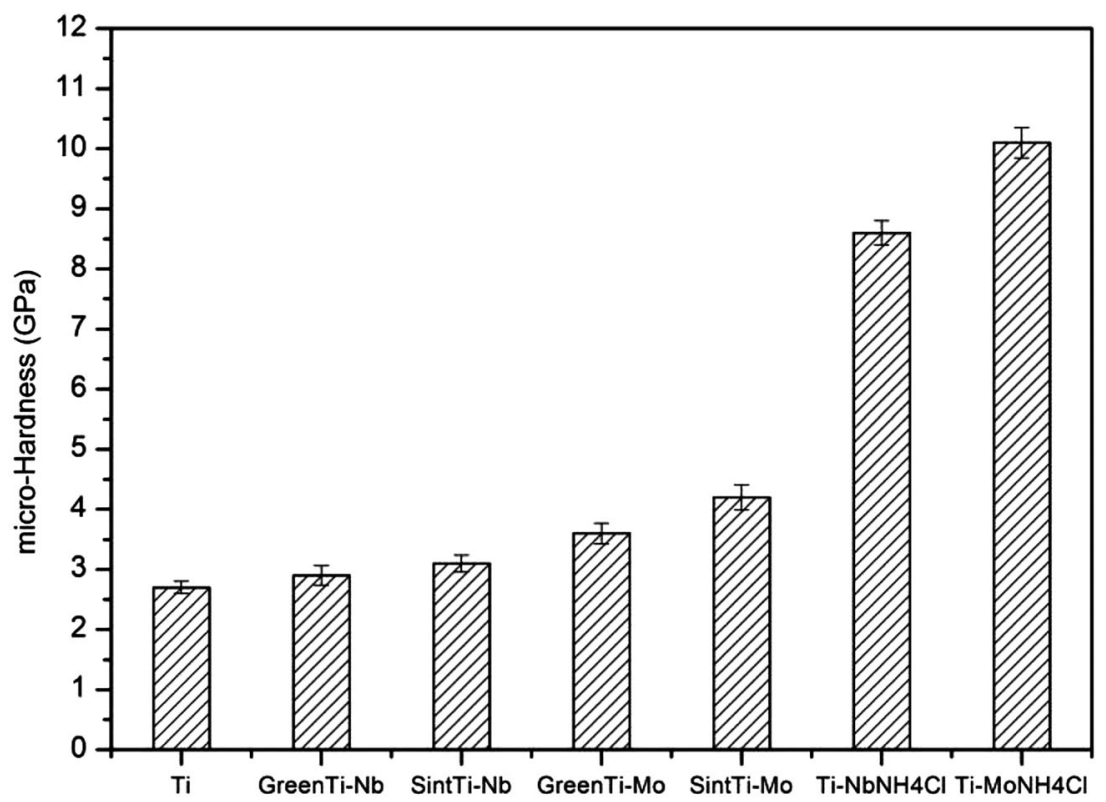

Figure 4. Vickers micro-hardness $\left(\mathrm{HV}_{0.1}\right)$ tests for all the modified materials. The data are presented in $\mathrm{GPa}$ showing the mean value of the measurements and the standard deviation with vertical bars.

respectively [29,30]. However, the activated samples exhibited higher elastic modulus around 125140 GPa mainly attributed to the TiN layer.

Figure 6 shows the diffusion layers depth together with the maximum indentation depth at $5 \mathrm{~N}$ and $15 \mathrm{~N}$. In all samples, the maximum indentation depth did not exceed the diffusion areas, reaching values close to $20 \mu \mathrm{m}$ for the samples with lower stiffness which corresponds to the upper part ( $\beta$-region). When comparing GreenTi-Nb and SintTi-Nb samples, higher porosity in the co-sintered samples seems to lead to a small increase of the indentation depth.

In this context, the surface porosity on the activated samples could suggest deeper indentation marks.
Nevertheless, these samples present the smallest values mainly attributed to their higher hardness. Therefore, it could be stated that hardness has a stronger influence on the maximum depth indentation than porosity, with hardness improvement resulting in smaller indentation depth with respect to $\mathrm{Ti}$.

\subsubsection{Nanoindentation: cross-sectional elastic modulus and nano-hardness}

Hardness and elastic modulus values from nanoindentation measurements on the materials cross-section are summarised in Figure 7. A decrease in the average elastic modulus value on the diffusion layers $(60-75 \mathrm{GPa})$ with respect to the substrate area was observed for all materials, except for the activated $\mathrm{Ti}-\mathrm{Mo}_{\mathrm{NH} 4 \mathrm{Cl}}$. As

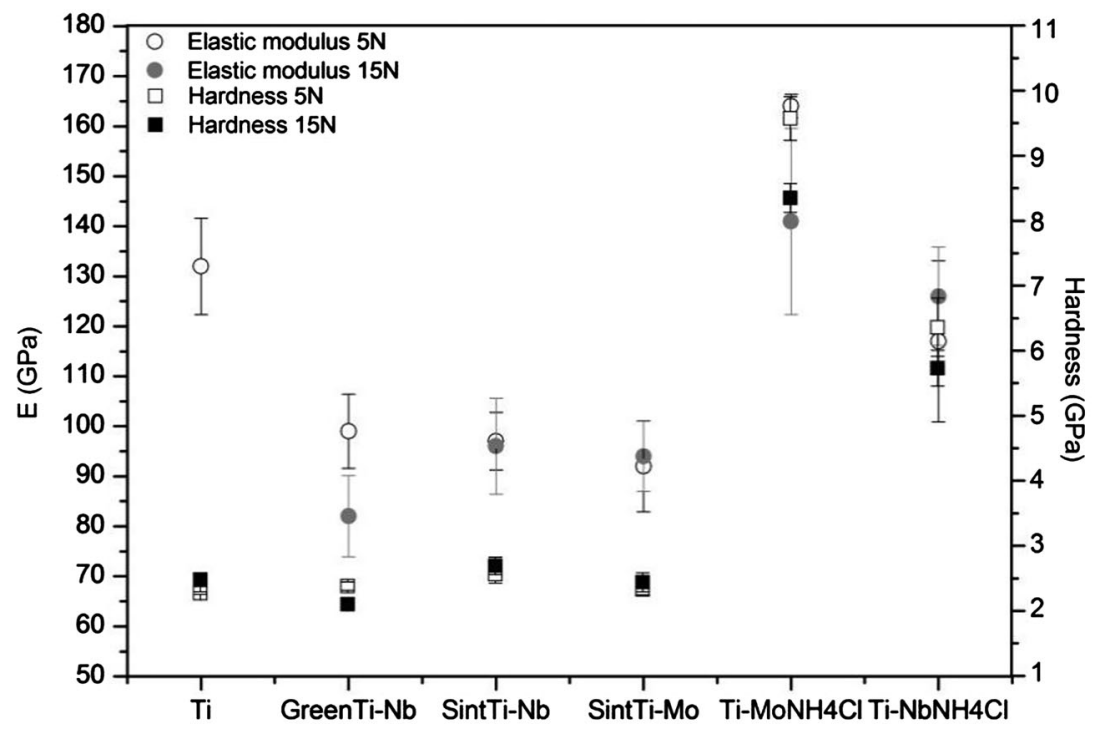

Figure 5. Elastic modulus and hardness values obtained from $5 \mathrm{~N}$ and $15 \mathrm{~N}$ indentation tests. The graph shows the mean value of the measurements and the standard deviation with vertical bars. 


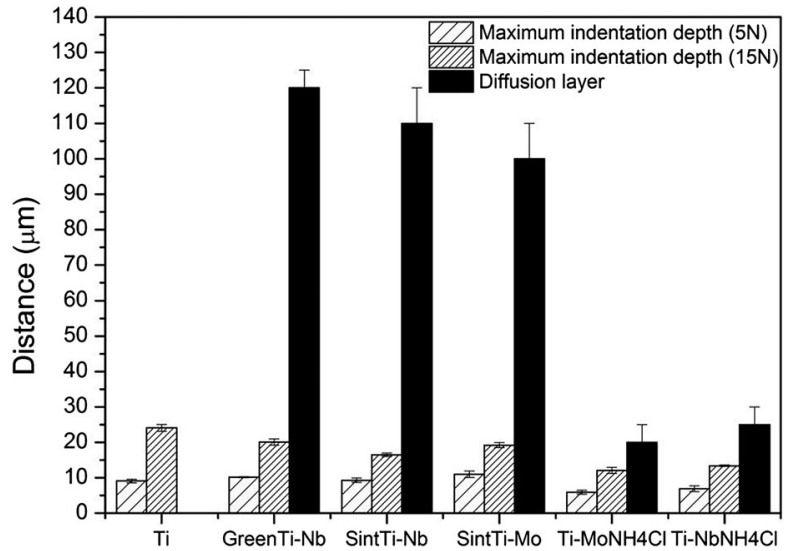

Figure 6. Comparison of the maximum indentation depth between $5 \mathrm{~N}$ and $15 \mathrm{~N}$ load for all the modified materials. The graph presents the mean value of the measurements and the standard deviation with vertical bars.

expected, the $\beta$-stabilising elements reduced the elastic modulus because of the $\beta$-phase formation, while the TiN layer from the $\mathrm{Ti}-\mathrm{Mo}_{\mathrm{NH} 4 \mathrm{Cl}}$ surface leads to increase in hardness but also elastic modulus. Furthermore, the elastic modulus seems to be slightly influenced by the initial state of the Ti substrate, with the GreenTi-Nb material presenting around $5 \mathrm{GPa}$ less with respect to SintTi-Nb. Similar results are reported in the literature, with the $\alpha$-phase transformation into $\beta$ or $\alpha+\beta$ phases influenced by composition (i.e. TixMo, TixMoyNb) [31,32]. Regarding hardness, values were higher in all the modified $\mathrm{Ti}$ materials around 4.5 GPa in agreement to that reported for a PM Ti$\mathrm{Nb}$ alloy [7]. This means twice the hardness of bare $\mathrm{Ti}$ and near three times in the case of $\mathrm{Ti}-\mathrm{Mo}_{\mathrm{NH} 4 \mathrm{Cl}}$.

Figure 8 shows the evolution of elastic modulus along depth where values corresponding to the diffusion layers are shown in striped areas while those from the substrate area in empty squares. As it can be seen, similar features were obtained on both $\mathrm{Ti}-\mathrm{Nb}$ and $\mathrm{Ti}-\mathrm{Mo}$ systems, Figure 8(a) and (b), respectively. As a result of gradient microstructures and compositions, a gradient in elastic modulus was found on all the modified materials. The lowest values around $60 \mathrm{GPa}$ were found closer to the surface $(15 \mu \mathrm{m}$ depth), whereas medium values around $80 \mathrm{GPa}$ at $50 \mu \mathrm{m}$ depth and above $110 \mathrm{GPa}$ in the substrate area. These values are related to the microstructure of the materials, since the lowest $\mathrm{E}$ values were found in the outer part which means in the $\beta$ region, the medium $E$ values getting deeper into the $\alpha+\beta$ region, and the highest $E$ values in the $\alpha$ region of the substrate area. However, E values corresponding to the a-phase were slightly higher with respect to Ti whose microstructure is composed of $\alpha$-single phase. This could be ascribed to the heat treatment performed to promote the diffusion after the sintering cycle which means two heat treatments compared with only the sintering treatment of titanium. This could be attributed to reduced porosity and thus increased elastic modulus in those regions without $\beta$-stabilising element. This also agrees to the fact that the $\mathrm{E}$ values from the substrate area on the modified green samples are lower than their respective modified sintered samples.

Figure 9 shows the evolution of elastic modulus with the $\mathrm{Nb}$ and Mo composition (Figure 9(a) and (b)), respectively. Regarding $\mathrm{Nb}$ composition (Figure 9(a)), the lowest $\mathrm{E}$ value reached was $54 \mathrm{GPa}$ with $20 \%$ of $\mathrm{Nb}$ on GreenTi-Nb material, while a slight increase up to $64 \mathrm{GPa}$ was obtained with a higher amount of $\mathrm{Nb}(30 \%)$ on SintTi-Nb. This behaviour could be attributed to the relative higher porosity remaining in

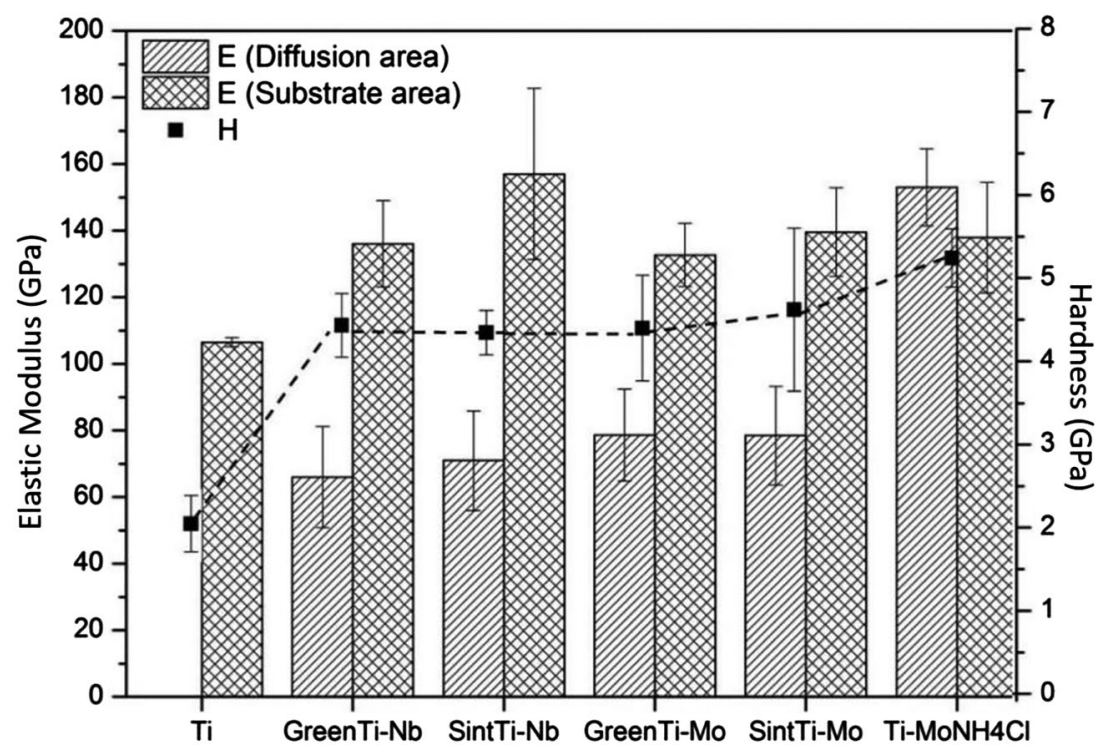

Figure 7. Comparison of the average values of the elastic modulus between diffusion and substrate areas. Mean hardness of each material. Data obtained from nano-indentation test. The graph shows the mean value of the measurements and the standard deviation with vertical bars. 
a)

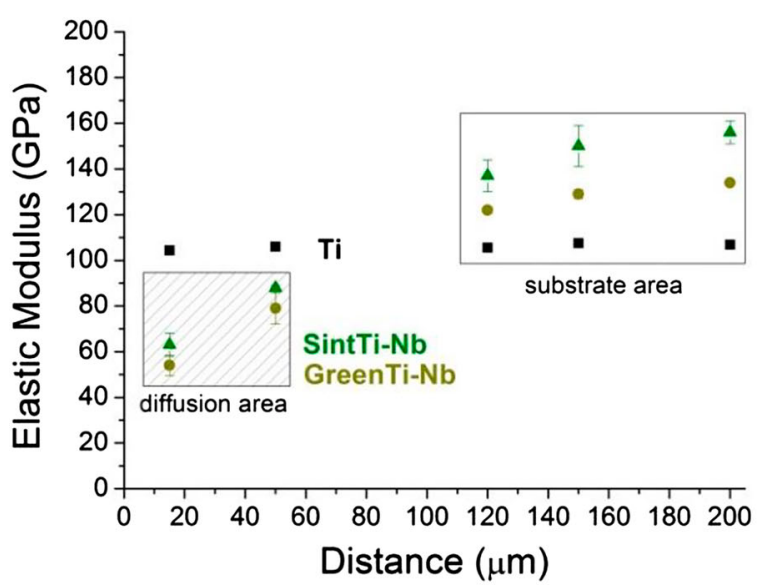

b)

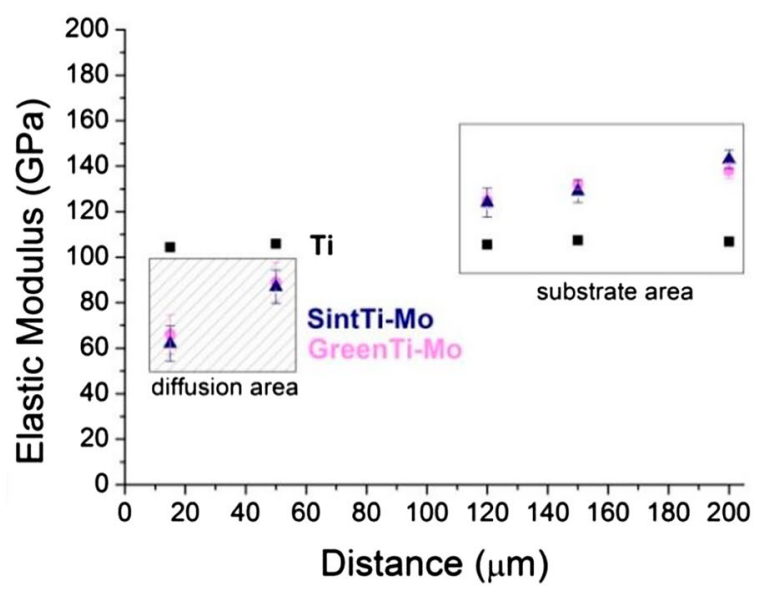

Figure 8. Evolution of elastic modulus as a function of distance on (a) Ti-Nb and (b) Ti-Mo systems. The graphs show the mean value of the measurements and the standard deviation with vertical bars.

a)

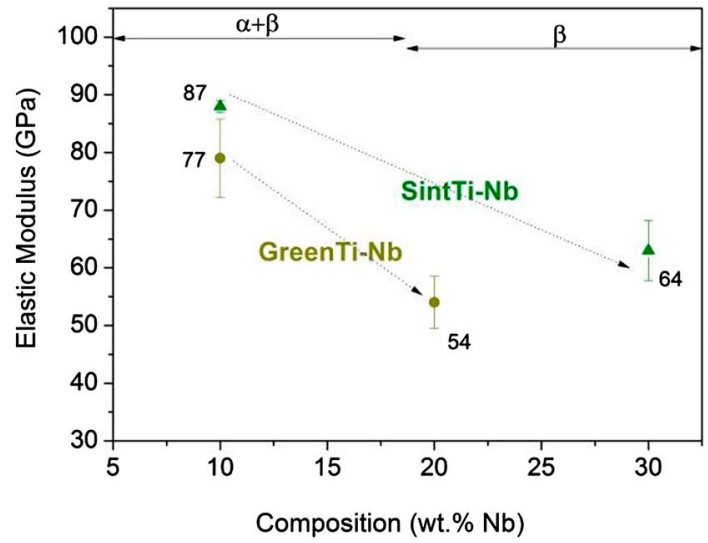

b)

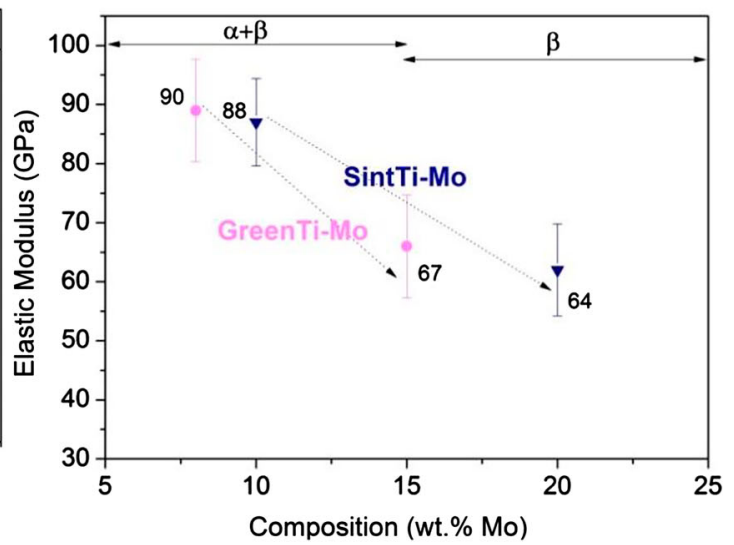

Figure 9. Evolution of elastic modulus as a function of (a) $\mathrm{Nb}$ and (b) Mo composition. The graphs show the mean value of the measurements and the standard deviation with vertical bars.

the Green material due to its fabrication route in only one single step. These $\mathrm{E}$ values correspond to the $\mathrm{Nb}$ rich region composed of stable $\beta$-phase as reported in the $\mathrm{Ti}-\mathrm{Nb}$ phase diagram [4]. When the $\mathrm{Nb}$ content decreased to $10 \%$ ( $\alpha+\beta$ region), E values raised up to 77 and $87 \mathrm{GPa}$, keeping the tendency of lower and higher elastic modulus on green and sintered samples, respectively. Similar values to those of our $\beta$-Ti surfaces around $60-70 \mathrm{GPa}$ were reported for $\beta$-Ti alloys composed of two $\beta$-stabilising elements in different compositions such as Ti15Zr10Nb, Ti27Nb13Zr or Ti30Cr10Nb [31,33,34].

The elastic modulus as a function of Mo composition is shown in Figure 9(b). The lowest $\mathrm{E}$ value reached was $63 \mathrm{GPa}$ on the SintTi-Mo sample with $20 \%$ of Mo. Whereas on GreenTi-Mo, as in the case of $\mathrm{Nb}$, a low value of $65 \mathrm{GPa}$ with only $15 \%$ of Mo was reached due to the slightly higher porosity. Similar to Figure 9(a), the microstructural change to $\alpha+\beta$ resulted in E values close to $90 \mathrm{GPa}$ with approximately $10 \%$ of Mo. Similar behaviour was reported for Ti-Mo alloys exhibiting $13 \%$ of Mo and $75 \mathrm{GPa}$ elastic modulus [14]. When comparing the $\beta$-stabiliser effect of $\mathrm{Nb}$ or $\mathrm{Mo}$ on $\mathrm{Ti}$, relative lower elastic modulus values were reached by $\mathrm{Nb}$ diffusion with respect to those achieved by Mo diffusion. A good in vitro biological response has been reported for $\mathrm{Ti}-\mathrm{Mo}-\mathrm{Nb}$ with different compositions and $\mathrm{E}$ values around $80 \mathrm{GPa}$ [32]. Therefore, this improvement in mechanical properties could lead to a promising biological response of our modified Ti surfaces.

\section{Conclusions}

The surface modification by $\mathrm{Nb}$ and Mo diffusion treatments into $\mathrm{Ti}$ substrates processed by powder metallurgy has been successfully achieved. Three different $\mathrm{Ti}-\mathrm{Nb}$ surfaces as well as three Ti-Mo surfaces have been designed. For the co-sintering and diffusion processes, well-defined gradients in microstructure $(\beta / \alpha+\beta / \alpha)$ and composition ( $\mathrm{Ti}-\mathrm{Nb}$ or $\mathrm{Ti}-\mathrm{Mo}$ ) with $\mathrm{Nb}$-rich or Mo-rich surfaces were 
obtained. These diffusion layers ranged from 90 to $120 \mu \mathrm{m}$ in depth while thermo-reactive diffusion led to $20-25 \mu \mathrm{m}$ porous surfaces with a TiN layer on surface.

Hardness and elastic modulus were measured at different scales: (i) surface Vickers micro-hardness $\left(\mathrm{HV}_{0.1}\right)$, (ii) $5 \mathrm{~N}$ and $15 \mathrm{~N}$ surface macro-indentation and (iii) cross-sectional nanoindentation. The microstructural gradient on the materials resulted in a gradient in mechanical properties as well as lower elastic modulus values at the $\mathrm{Nb}$-rich or Mo-rich regions composed of fully $\beta$-phase: $54 \mathrm{GPa}(\mathrm{GreenTi}-\mathrm{Nb}$ ), $64 \mathrm{GPa}$ (SintTi-Nb), $65 \mathrm{GPa}$ (GreenTi-Mo) and $63 \mathrm{GPa}$ (SintTi-Mo). A decrease up to $40-50 \%$ with respect to the elastic modulus of two of the most used $\mathrm{Ti}$ alloys for biomedical applications: $\mathrm{Cp}-\mathrm{Ti}$ (102-105 GPa) and Ti6Al4V (110-114 GPa) was achieved. The hardness of the modified surfaces was around $4 \mathrm{GPa}$, twice the value of pure Ti. The activated material exhibited the hardest surface, while a decrease in elastic modulus was not reached due to the lack of Mo diffusion and remanence of the $\alpha$-phase. Therefore, the improved hardness and decreased elastic modulus of these modified Ti surfaces enhanced the mechanical properties of Ti making them potentially suitable for biomedical applications.

\section{Disclosure statement}

No potential conflict of interest was reported by the authors.

\section{Funding}

The authors would like to thank the funding provided for this research by the Regional Government of Madrid (program MULTIMAT-CHALLENGE-CM, ref. S2013/MIT2862), and by the Ministry of Economy and Competitiveness of Spain (program MINECO, ref. PCIN-2016-123 and Ramón y Cajal contract RYC-2014-15014).

\section{Notes on contributors}

J. Ureña was born on November 26th, 1990 in Jaén/Spain. She studied chemistry at the University of Jaén from 2008 to 2012. Now, she is working in her PhD in material engineering from 2014 at the Group of Powder Metallurgy (GTP) of the University Carlos III of Madrid.

E. Tejado was born on September 24th, 1985 in Cáceres/ Spain. She studied Building and Materials Engineering at the University of Extremadura. In 2017 she finished her $\mathrm{PhD}$ at the Materials Science Department of the Technical University of Madrid where she is actually working as an Assistant Professor.

J. Y. Pastor was born on October 26th, 1965 in Madrid/ Spain. He studied physics and physics of materials in the Complutense University of Madrid from 1983 to 1988. In 1993, he finished his PhD in the Complutense University of Madrid. Now, he is Full Professor of Material Science and Engineering and Director of the Materials for the Future
Cluster of the International Campus of Excellence-Moncloa in the Technical University of Madrid.

F. Velasco has a $\mathrm{PhD}$ in Materials Science and Metallurgical Engineering in 1995 at University Politecnica of Madrid, Spain. He is professor at University Carlos III of Madrid since 1997. He has carried out research in sintered materials, corrosion and oxidation processes, adhesives, surface treatments and organic coatings.

S. Tsipas received her MEng degree in Materials Science and Engineering from Imperial College, London, United Kingdom in 2000 and completed her PhD in 2006 at the Department of Materials Science and Metallurgy in the University of Cambridge, United Kingdom. She was a post-doctoral researcher at the University Complutense of Madrid, Spain in 2006-2008. Since 2008 she works at University Carlos III of Madrid, Spain.

A. Jiménez-Morales is $\mathrm{PhD}$ in Industrial Technology (1999) from University Carlos III of Madrid, Spain. She is member of the Powder Metallurgy Group of the University Carlos III of Madrid. She has received the Award of Excellence in 2015 by the Social Council of the UC3M, the Santander Bank and Airbus. Her research is mainly focused on coatings and surface treatments, and powder injection molding processing.

E. Gordo is PhD in Mining Engineering (1998) from Technical University of Madrid, Spain. She obtained recently a full professor position at the University Carlos III of Madrid, Spain, where she was associated professor from 2003. Her research is mainly focused in the design and processing of titanium alloys and hardmetals by powder metallurgy.

[1] Niinomi M. Mechanical biocompatibilities of titanium alloys for biomedical applications. J Mech Behav Biomed Mater. 2008;1(1):30-42.

[2] Hussein M, Mohammed A, Al-Aqeeli N. Wear characteristics of metallic biomaterials: a review. Materials (Basel). 2015;8(5):2749-2768.

[3] Geetha M, Singh AK, Asokamani R, et al. Ti based biomaterials, the ultimate choice for orthopaedic implants - a review. Prog Mater Sci. 2009;54(3):397-425.

[4] Zhu L, Zhang Q, Chen Z, et al. Measurement of interdiffusion and impurity diffusion coefficients in the bcc phase of the $\mathrm{Ti}-\mathrm{X}(\mathrm{X}=\mathrm{Cr}, \mathrm{Hf}, \mathrm{Mo}, \mathrm{Nb}, \mathrm{V}, \mathrm{Zr})$ binary systems using diffusion multiples. J Mater Sci. 2017;52(6):3255-3268.

[5] Liu X, Chu PK, Ding C. Surface modification of titanium, titanium alloys, and related materials for biomedical applications. Mater Sci Eng R Reports. 2004;47 (3-4):49-121.

[6] Goriainov V, Cook R, Latham JM, et al. Bone and metal: An orthopaedic perspective on osseointegration of metals. Acta Biomater. 2014;10(10):4043-4057.

[7] Sharma B, Kumar S, Ameyama K. Microstructure and properties of beta $\mathrm{Ti}-\mathrm{Nb}$ alloy prepared by powder metallurgy route using titanium hydride powder. J Alloys Compd. 2016;656:978-986. 
[8] Li Y, Yang C, Zhao H, et al. New developments of Tibased alloys for biomedical applications. Materials (Basel). 2014;7(3):1709-1800.

[9] Fan A, Ma Y, Yang R, et al. Friction and wear behaviors of Mo-N modified Ti6Al4V alloy in Hanks' solution. Surf Coatings Technol. 2013;228:S419-S423.

[10] Wilson JCA, Ban S, Housden J, et al. On the response of Ti-6Al-4V and Ti-6Al-7Nb alloys to a Nitron-100 treatment. Surf Coat Technol. 2014;260:335-346.

[11] Ng KW, Man HC, Cheng FT, et al. Laser cladding of copper with molybdenum for wear resistance enhancement in electrical contacts. Appl Surf Sci. 2007;253 (14):6236-6241.

[12] Viteri D, Barandika G, Bayo R, et al. Development of Ti-C-N coatings with improved tribological behavior and antibacterial properties. J Mech Behav Biomed Mater. 2016;55:75-86.

[13] Tsipas SA, Gordo E, Jiménez-Morales A. Oxidation and corrosion protection by halide treatment of powder metallurgy $\mathrm{Ti}$ and Ti6Al4V alloy. Corros Sci. 2014;88:263-274.

[14] Almeida A, Gupta D, Loable C, et al. Laser-assisted synthesis of Ti-Mo alloys for biomedical applications. Mater Sci Eng C. 2012;32(5):1190-1195.

[15] Mandracci P, Mussano F, Rivolo P, et al. Surface treatments and functional coatings for biocompatibility improvement and bacterial adhesion reduction in dental implantology. Coatings. 2016. 6(1):7.

[16] Sullivan SJL, Topoleski LDT. Surface modifications for improved wear performance in artificial joints: a review. Miner Met Mater Soc. 2015;67(11):2502-2517.

[17] Mohammed MT, Khan ZA, Siddiquee AN. Surface modifications of titanium materials for developing corrosion behavior in human body environment: a review. Procedia Mater Sci. 2014;6(Icmpc):1610-1618.

[18] Bolzoni L, Esteban PG, Ruiz-Navas EM, et al. Mechanical behaviour of pressed and sintered titanium alloys obtained from master alloy addition powders. J Mech Behav Biomed Mater. 2012;15:33-45.

[19] Carman A, Zhang LC, Ivasishin OM, et al. Role of alloying elements in microstructure evolution and alloying elements behaviour during sintering of a near- $\beta$ titanium alloy. Mater Sci Eng A. 2011;528(3):1686-1693.

[20] Ureña J, Mendoza C, Ferrari B, et al. Surface modification of powder metallurgy titanium by colloidal techniques and diffusion processes for biomedical applications. Adv Eng Mater. 2017;19(6):1-8.

[21] Tsipas SA, Gordo E. Molybdeno-aluminizing of powder metallurgy and wrought $\mathrm{Ti}$ and $\mathrm{Ti}-6 \mathrm{Al}-4 \mathrm{~V}$ alloys by pack cementation process. Mater Charact. 2016;118:494-504.

[22] Sidambe AT. Biocompatibility of advanced manufactured titanium implants - a review. Materials (Basel). 2014;7:8168-8188.

[23] Divinski S, Hisker F, Klinkenberg C, et al. Niobium and titanium diffusion in the high niobium-containing $\mathrm{Ti}$ 54Al-10Nb alloy. Intermetallics. 2006;14(7):792-799.

[24] Cardoso FF, Ferrandini PL, Lopes ESN, et al. Ti-Mo alloys employed as biomaterials: effects of composition and aging heat treatment on microstructure and mechanical behavior. J Mech Behav Biomed Mater. 2014;32:31-38.

[25] Mi-Kyung H, Jai-Youl K, Moon-Jin H, et al. Effect of $\mathrm{Nb}$ on the microstructure, mechanical properties, corrosion behavior, and cytotoxicity of $\mathrm{Ti}-\mathrm{Nb}$ alloys. Materials (Basel). 2015;8:5986-6003.

[26] Peng XM, Xia CQ, Liu YY, et al. Surface molybdenizing on titanium by halide-activated pack cementation. Surf Coatings Technol. 2009;203(20-21):3306-3311.

[27] Li J, Xia C, Gu Y. Effect of temperature on microstructure of molybdenum diffusion coating on titanium substrate. J Cent South Univ Technol. 2004;11(1):1518.

[28] Gong J, Wu J, Guan Z. Examination of the indentation size effect in low-load Vickers hardness testing of ceramics. J Eur Ceram Soc. 1999;19:2625-2631.

[29] Nnamchi PS, Njoku RE, Fasuba OA. Alloy design and property evaluation of Ti-Mo-Nb-Sn alloy for biomedical applications. Niger J Technol. 2013;32(3):410416.

[30] Oliveira NTC, Guastaldi AC. Electrochemical stability and corrosion resistance of Ti-Mo alloys for biomedical applications. Acta Biomater. 2009;5(1):399-405.

[31] Matkovic P. Alloy design and property evaluation of new Ti- Cr-Nb alloys. Mater Des. 2012;33:26-30.

[32] Neacsu P, Gordin D, Mitran V, et al. In vitro performance assessment of new beta $\mathrm{Ti}-\mathrm{Mo}-\mathrm{Nb}$ alloy compositions. Mater Sci Eng C. 2015;47:105-113.

[33] Calderon-Moreno JM, Vasilescu C, Drob SI, et al. Microstructural and mechanical properties, surface and electrochemical characterisation of a new $\mathrm{Ti}-\mathrm{Zr}$ $\mathrm{Nb}$ alloy for implant applications. J Alloys Compd. 2014;612:398-410.

[34] Mendes MWD, Ágreda CG, Bressiani AHA, et al. A new titanium based alloy $\mathrm{Ti}-27 \mathrm{Nb}-13 \mathrm{Zr}$ produced by powder metallurgy with biomimetic coating for use as a biomaterial. Mater Sci Eng C. 2016;63:671677. 